\title{
Antibodies from Patients with Heparin-induced Thrombocytopenia/Thrombosis Are Specific for Platelet Factor 4 Complexed with Heparin or Bound to Endothelial Cells
}

Gian P. Visentin, Sheila E. Ford, J. Paul Scott, and Richard H. Aster

Blood Research Institute. The Blood Center of Southeastern Wisconsin, and the Departments of Medicine, Pathology, and Pediatrics, Medical College of Wisconsin, Milwaukee, Wisconsin 53226

\begin{abstract}
Heparin-induced thrombocytopenia/thrombosis (HITP) is thought to be mediated by immunoglobulins that activate platelets in the presence of pharmacologic concentrations of heparin, but the molecular basis for this relatively common and often serious complication of heparin therapy has not been established. We found that plasma from each of 12 patients with HITP contained high titer $(\geq 1: 200)$ antibodies that reacted with immobilized complexes of heparin and platelet factor 4 (PF4), a heparin-binding protein contained in platelet alphagranules. Recombinant human PF4 behaved similarly to PF4 isolated from platelets in this assay system. Complexes formed at an apparent heparin/PF4 molecular ratio of $\sim 1: 2$ (fresh heparin) and $\sim 1: 12$ (outdated heparin) were most effective in binding antibody. Immune complexes consisting of PF4, heparin, and antibody reacted with resting platelets; this interaction was inhibited by a monoclonal antibody specific for the Fc $\gamma$ RII receptor and by excess heparin. Human umbilical vein endothelial cells, known to express heparin-like glycosaminoglycan molecules on their surface, were recognized by antibody in the presence of PF4 alone; this reaction was inhibited by excess heparin, but not by anti-Fc $\gamma$ RII. Antibodies reactive with heparin/PF4 were not found in normal plasma, but IgG and IgM antibodies were detected at dilutions of 1:10 (IgG) and 1:50 (IgM) in 3 of 50 patients $(6 \%)$ with other types of immune thrombocytopenia. These findings indicate that antibodies associated with HITP react with PF4 complexed with heparin in solution or with glycosaminoglycan molecules on the surface of endothelial cells and provide the basis for a new hypothesis to explain the development of thrombocytopenia with thrombosis or disseminated intravascular coagulation in patients sensitive to heparin. (J. Clin. Invest. 1994. 93:81-88.) Key words: ELISA • glycosaminoglycan • IgG • IgM • flow cytometry
\end{abstract}

\section{Introduction}

Heparin-induced thrombocytopenia (HITP) ${ }^{1}$ associated with thromboembolism was first described more than 30 years ago

Address correspondence to Dr. Gian P. Visentin, Blood Research Institute, Blood Center of Southwestern Wisconsin, 8727 Watertown Plank Road, Milwaukee, WI 53226-3548.

Received for publication 4 August 1993 and in revised form XXX.

1. Abbreviations used in this paper: DTAF, dichlorotriazinylamino florescein; HITP, heparin-induced thrombocytopenia; HUVEC, human umbilical vein endothelial cells; PF4, platelet factor 4; RCD, Ringer's citrate dextrose.

J. Clin. Invest.

(C) The American Society for Clinical Investigation. Inc.

0021-9738/94/01/0081/08 $\$ 2.00$

Volume 93, January 1994, 81-88
$(1,2)$. Hundreds of cases have since been reported and HITP is now recognized as an important cause of morbidity and mortality in patients receiving heparin therapy $(3,4)$. HITP differs from most other forms of drug-induced thrombocytopenia in that the responsible antibodies activate platelets in the presence of optimal concentrations of heparin, rather than merely binding to platelets to promote their destruction (3-5). This activation can be blocked in vitro by monoclonal antibodies specific for the platelet Fc receptor ( $F c \gamma$ RII ) (6), suggesting that heparin-induced antibodies somehow interact with heparin to form platelet-activating immune complexes. However, attempts to demonstrate such complexes and their binding to intact platelets have yielded negative or equivocal results $(3,7,8)$.

The laboratory diagnosis of HITP is made with tests in which aggregation of platelets is triggered in platelet-rich plasma or release of radiolabeled serotonin from platelets is induced by patient serum in the presence of heparin $(3,4)$. Recently, Amiral et al. (9) described an assay for heparin-induced antibodies based on their reaction with immobilized complexes of heparin and platelet factor 4 (PF4), a constituent of platelet alpha granules (9). In this report, we confirm their observation and show that the antibodies can be of the $\mathrm{IgM}$ as well as the IgG class. We also describe the binding of complexes consisting of heparin, PF4, and IgG to resting platelets and PF4-dependent, but heparin-independent, binding of antibodies to cultured human umbilical vein endothelial cells (HUVEC). On the basis of these findings, we propose a new hypothesis for the pathogenesis of HITP and the associated thromboembolic phenomena.

\section{Methods}

Chemicals and reagents. These were obtained from the following sources: affinity-purified $F\left(a b^{\prime}\right)_{2}$ goat anti-human IgG ( $\gamma$ chain specific), donkey anti-human IgM ( $\mu$ chain specific), goat anti-rabbit $\operatorname{IgG}(\gamma$ chain specific $)$, and donkey anti-goat $\operatorname{IgG}(\mathrm{H}+\mathrm{L}$ chain specific) labeled with dichlorotriazinylamino fluorescein (DTAF) from Jackson Immune Research (Westgrove, PA); affinity-purified, alkaline phosphatase-labeled goat anti-mouse $\operatorname{IgG}(\gamma$ chain specific), anti-human IgG ( $\gamma$ chain specific), anti-human IgM ( $\mu$-chain specific), anti-rabbit IgG $(\mathrm{H}+\mathrm{L}$ chain specific $)$, and $p$-nitrophenyl phosphate from Zymed Labs., Inc. (S. San Francisco, CA); rabbit and goat IgG specific for human PF4 from Celsus Laboratories (Cincinnati, $\mathrm{OH}$ ) and Incstar Co. (Stillwater, MN), respectively; heparin-agarose containing $\sim 792 \mu \mathrm{g}$ of heparin $/ \mathrm{ml}$ of packed gel, ecteola cellulose (epichlorohydrin triethanolamine cellulose), PMSF, Tween-20, and $\mathrm{PGE}_{1}$ from Sigma Chemical Co. (St. Louis, MO); FCS and horse serum from Hyclone Labs. (Logan, UT). The T1 short peptide 11 mer of the platelet thrombin receptor (SFLLRNPNDKY) $(10,11)$ was synthesized by the peptide core laboratory of the Blood Research Institute (Milwaukee, WI). Monoclonal antibodies were generously provided by the following individuals: IV.3 specific for the Fc $\gamma$ RII receptor from Dr. Clark Anderson (Ohio State University, Columbus, $\mathrm{OH}$ ), S12 specific for P-selectin from Dr. Rodger McEver (University of Oklahoma, Oklahoma City, OK), AP-1 specific for glycoprotein Ib 
and AP-2 specific for the glycoprotein IIb/IIIa complex from Drs. Robert Montgomery (Blood Research Institute, Milwaukee, WI) and Thomas Kunicki (Scripps Research Institute, La Jolla, CA). Recombinant human PF4 was a gift from Dr. Mortimer Poncz (University of Pennsylvania, Philadelphia, PA).

Two lots of injectable heparin derived from porcine intestinal mucosa (Elkins-Sinn; ESI Pharmaceuticals, Cherry Hill, NJ) were used. One of these (lot 1) outdated 3 mo before the studies were initiated. The other (lot 2) carried an outdate of May 1996. The specific activity of the two lots were 169 and $179 \mathrm{IU} / \mathrm{mg}$, respectively. Both had been stored at $15-30^{\circ} \mathrm{C}$ according to the manufacturer's instructions, and their anticoagulant activities, as measured by their capacity to prolong the partial thromboplastin time, were indistinguishable. A limited number of studies were also done with porcine heparin from Lyphomed (Deerfield, IL) and bovine heparin from the Upjohn Co. (Kalamazoo, MI).

Buffers. Ringer's citrate dextrose (RCD) buffer contained 0.108 $\mathrm{mol} /$ liter $\mathrm{NaCl}, 0.038 \mathrm{~mol} /$ liter $\mathrm{KCl}, 0.0017 \mathrm{~mol} /$ liter $\mathrm{NaHCO}_{3}$, $0.0212 \mathrm{~mol} /$ liter $\mathrm{Na}_{3} \mathrm{C}_{6} \mathrm{H}_{5} \mathrm{O}_{7} \cdot 2 \mathrm{H}_{2} \mathrm{O}, 0.0278 \mathrm{~mol} /$ liter $\mathrm{C}_{6} \mathrm{H}_{12} \mathrm{O}_{6}$, $0.0011 \mathrm{~mol} /$ liter $\mathrm{MgCl}_{2} \mathrm{O} \cdot 6 \mathrm{H}_{2} \mathrm{O}$; phosphate buffer (PB) contained $0.02 \mathrm{~mol} /$ liter, pH 7.2; PBS contained PB with $0.145 \mathrm{~mol} /$ liter $\mathrm{NaCl}$; PBS-Tw contained PBS with Tween-20, $0.05 \%$.

Patient samples. Plasma samples from 12 patients who developed thrombocytopenia with or without thrombosis while receiving prophylactic heparin therapy and whose plasma had tested positive in the serotonin release test for heparin-induced antibodies (12) were studied. The samples were collected within $2 \mathrm{~d}$ of the time heparin was discontinued. 10 were anticoagulated with citrate and 2 with EDTA. The patients, eight women and four men, ranged in age from 51 to $75 \mathrm{yr}$. Five patients experienced thrombotic symptoms while receiving heparin, including deep vein thrombosis, pulmonary embolism, and jugular vein thrombosis. One patient died from thromboembolic complications. Each plasma sample was adsorbed with ecteola cellulose equilibrated in PBS to remove residual heparin that might be present (13) by adding $70 \mathrm{mg}$ ecteola to $1 \mathrm{ml}$ of plasma and incubating for $90 \mathrm{~min}$ at $4^{\circ} \mathrm{C}$ with occasional agitation, and centrifuging at $14,000 \mathrm{~g}$ for $1 \mathrm{~min}$. In preliminary studies in which heparin was added to plasma containing heparin-induced antibody, we found that this treatment was capable of removing at least $10 \mathrm{U}$ of heparin $/ \mathrm{ml}$, far more than the amount that might be present after recent heparin therapy. Plasma from patients with other types of thrombocytopenia were obtained from the Platelet Antibody Laboratory of The Blood Center of Southeastern Wisconsin, to which they had been referred for serologic testing.

Isolation of platelets. Platelets were isolated from freshly collected blood anticoagulated with acid citrate dextrose sufficient to produce a $\mathrm{pH}$ of 6.5 and were washed three times in RCD buffer, $\mathrm{pH} 6.5$, containing $50 \mathrm{ng} / \mathrm{ml} \mathrm{PGE}_{1}$. The washed platelets were nonactivated by the criterion that their mean fluorescence intensity in flow cytometry after incubation with fluorescein-labeled monoclonal antibody $\mathrm{S} 12$ specific for P-selectin was not significantly different from that of platelets incubated with equal amounts of fluorescein-labeled normal mouse IgG. A marked increase in S12 binding occurred when platelets were activated by the $\mathrm{T} 1$ short peptide of the platelet thrombin receptor.

Purification of PF4. PF4 was purified according to Medici et al. (14), with minor modifications. $10 \mathrm{U}$ of platelets $\leq 1 \mathrm{~d}$ old from randomly chosen whole blood donors was pooled and centrifuged at $400 \mathrm{~g}$ for $10 \mathrm{~min}$ to remove red cells. The platelet-rich plasma was pelleted at $1,200 \mathrm{~g}$, washed three times in RCD buffer, $\mathrm{pH} 6.5$, containing EDTA $0.002 \mathrm{M}$, and resuspended in PBS containing $0.001 \mathrm{M} \mathrm{CaCl}_{2}$, and $0.0014 \mathrm{M}$ PMSF in dimethylsulfoxide at a concentration of $10^{10}$ platelets $/ \mathrm{ml}$ in a total volume of $50 \mathrm{ml}$. Platelet release was induced with $\mathrm{T} 1$ short peptide $(10,11)$ at a final concentration of $5 \mu \mathrm{M}$ for $20 \mathrm{~min}$ at $37^{\circ} \mathrm{C}$ with occasional shaking. The activated platelets were then pelleted at $3,000 \mathrm{~g}$ for $30 \mathrm{~min}$ at $4^{\circ} \mathrm{C}$. Ammonium sulfate was added to the supernatant at $50 \%$ saturation and the mixture was incubated at $4^{\circ} \mathrm{C}$ overnight. The precipitate was discarded and the final supernatant was dialyzed exhaustively against PBS at $4^{\circ} \mathrm{C}$. The dialyzed supernatant $(\sim 250 \mathrm{ml})$ was then incubated with $20 \mathrm{ml}$ of packed heparin-Agarose beads for $4 \mathrm{~h}$ at $4^{\circ} \mathrm{C}$ with gentle stirring. The beads were washed se- quentially with 3 vol each of $0.145 \mathrm{M}$ PB-NaCl, $0.8 \mathrm{M}$ PB-NaCl (to remove $\beta$-thromboglobulin and thrombospondin) and resuspended in 1.6 M PB- $\mathrm{NaCl}$ to release bound PF4. The final eluate was concentrated using the Centriprep 10 (Amicon, Beverly, MA) to a 5-ml volume, dialyzed against PBS at $4^{\circ} \mathrm{C}$, and treated for $1 \mathrm{~h}$ at $4^{\circ} \mathrm{C}$ with an excess of ecteola cellulose equilibrated in PBS to remove residual antithrombin-III. The supernatant was then centrifuged, and was shown to contain a single protein of $\sim 7.8 \mathrm{kD}$ by Coomassie blue stain after electrophoresis in a $15 \%$ SDS-polyacrylamide gel. Identification of this band as the PF4 monomer was confirmed by Western blotting with rabbit anti-human PF4.

Serotonin release. The serotonin release test was performed as described by Sheridan et al. (12) with minor modifications (15). Washed platelets labeled with $\left[{ }^{14} \mathrm{C}\right]$ serotonin were incubated with aliquots of patient plasma (recalcified and dialyzed) and $0.1 \mathrm{U} / \mathrm{ml}$ heparin in albumin-free Tyrode's buffer containing $0.002 \mathrm{M} \mathrm{CaCl}_{2}$ and $0.001 \mathrm{M}$ $\mathrm{MgCl}_{2}$ for $60 \mathrm{~min}$ at room temperature with gentle agitation. Release of serotonin at least $3 \mathrm{SD}$ in excess of that obtained with normal plasma was considered positive. Specificity of the reactions was confirmed by the absence of release when heparin was absent or was present in high concentration $(100 \mathrm{U} / \mathrm{ml})$.

PF4/heparin ELISA. The ratio of heparin/PF4 required to produce complexes capable of binding heparin-induced antibodies was determined in preliminary studies (see Results). Initial studies were done with a lot of heparin that had outdated several months previously (lot 1). 50- $\mu$ l aliquots of PF4 were mixed with heparin at various concentrations and incubated overnight at $4^{\circ} \mathrm{C}$ in the wells of a polystyrene microtiter plate (Easywash; Corning, Corning, NY). The trays were washed three times with PBS-Tw and blocked for $30 \mathrm{~min}$ at room temperature with PBS-Tw, FCS $20 \%$. $50 \mu$ of plasma diluted 1:10 or 1:50 in PBS was added to each well and incubated for $60 \mathrm{~min}$ at room temperature (RT). After three washes with PBS-Tw, bound IgG and/ or IgM was detected by adding alkaline phosphatase-labeled goat antihuman IgG or IgM diluted 1:1,000 in PBS-Tw-FCS (10\%), followed by incubation for $1 \mathrm{~h}$ at room temperature, washing four times, and incubation with $p$-nitrophenyl phosphate substrate for $1 \mathrm{~h}$. The reaction was stopped with $1 \mathrm{~N} \mathrm{NaOH}$ and absorbance was read at $405 \mathrm{~nm}$ using $650 \mathrm{~nm}$ for reference values. Reactions were considered positive when the mean OD (triplicate determinations) obtained with PF4/heparin complex was at least 3 SD greater than the value obtained with PF4 alone.

Binding of IgG and IgM to platelets. Binding of IgG and IgM to platelets was assayed by flow cytometry as described previously (16), with minor modifications. In brief, $10^{7}$ washed platelets from a normal group $\mathrm{O}$ donor in $25 \mu \mathrm{l} \mathrm{PBS}_{\mathrm{PGE}} \mathrm{PG}_{1}$ were aliquoted into polypropylene microtiter wells (MIC 2000; Dynatech, Chantilly, VA) pretreated with $1 \%$ BSA. $25 \mu$ l of plasma alone, plasma plus PF4, plasma plus heparin, or plasma plus heparin and PF4 together was then added in triplicate to produce final concentrations of 1:10 plasma, $10 \mu \mathrm{g} / \mathrm{ml} \mathrm{PF} 4$, and 0.05 $\mathrm{U} / \mathrm{ml}$ heparin. The mixtures were incubated for $60 \mathrm{~min}$ at room temperature, washed twice in PBS-PGE ${ }_{1}$, incubated with $50 \mu$ l DTAF-labeled $\mathrm{F}\left(\mathrm{ab}^{\prime}\right)_{2}$ goat anti-human IgG or donkey anti-human IgM at 1:80 dilution for $30 \mathrm{~min}$ at room temperature in the dark. After two additional washes in PBS-PGE 1 , the cells were suspended in $1 \mathrm{ml}$ of PBS and immediately analyzed on a FACStar Plus ${ }^{\oplus}$ flow cytometer (Becton \& Co., Dickinson Mountain View, CA ) equipped with a 2-W argon ion laser. Fluorescein fluorescence was detected through a $530 \pm 30-\mathrm{nm}$ band-pass filter. Logarithmic amplification was used for the forward scatter, side scatter, and fluorescence signal. Fluorescence and size calibrations were done using Fluoresbrite beads (PolySciences, Nices, IL). Green photomultiplier tube (PMT) voltages were optimized for each series of studies. The fluorescence histogram was obtained by acquisition of 10,000 ungated events. Data were analyzed with Lysys II software (Becton Dickinson \& Co.). Reactions were considered positive when mean platelet fluorescence intensity exceeded that of controls by $>3$ SD.

Binding of IgG and IgM to HUVEC. HUVEC were isolated from human umbilical vein cords by collagenase digestion and cultured (17, 
18). The cells were grown to subconfluency (85-95\% confluent) in T75 flasks (Corning) in RPMI 1640 (Celox, Hopkins, MN) supplemented with $15 \%$ horse serum, $100 \mu \mathrm{g} / \mathrm{ml}$ endothelial cell growth supplement (Collaborative Research Inc., Lexington, MA), and $100 \mu \mathrm{g} /$ $\mathrm{ml}$ heparin (from porcine intestinal mucosa; Sigma Chemical Co., St. Louis, MO), $100 \mathrm{U} / \mathrm{ml}$ penicillin, and $100 \mu \mathrm{g} / \mathrm{ml}$ streptomycin. Cell cultures were incubated at $37^{\circ} \mathrm{C}$ in a water-saturated atmosphere of $95 \%$ air, $5 \% \mathrm{CO}_{2}$, and were used between the second and the fourth passage. For flow cytometric studies, endothelial cells were detached from the tissue culture plate with PBS, $10 \%$ FCS containing $10 \mathrm{mM}$ of EDTA, and washed twice with PBS- $10 \%$ FBS. $5 \times 10^{5}$ cells were resuspended in PBS, FCS, $\mathrm{NaN}_{3}(0.02 \%)$ and were treated with patient plasma in the presence and absence of PF4 and heparin as described in Results. Bound IgG and IgM were assayed as described above for platelets, except that a linear rather than a logarithmic scale was used to evaluate forward scatter.

\section{Results}

Determination of the optimum heparin/PF4 ratio for formation of complexes recognized by heparin-induced antibodies. Complexes formed in mixtures containing heparin (lot 1$)$ in concentrations ranging from 0.01 to $0.5 \mathrm{U} / \mathrm{ml}$ and purified $\mathrm{PF} 4$ at concentrations ranging from 5 to $50 \mu \mathrm{g} / \mathrm{ml}$ were immobilized (see Methods) in triplicate in the wells of a polystyrene microtiter plate and used as targets for heparin-induced antibodies. Results obtained with the plasma of patient 1 are shown in Fig. $1 \mathrm{~A}$. IgG bound readily to complexes formed in mixtures of $0.05 \mathrm{U} / \mathrm{ml}$ heparin and $10 \mu \mathrm{g} / \mathrm{ml} \mathrm{PF} 4$ or $0.1 \mathrm{U} / \mathrm{ml}$ heparin and $25 \mu \mathrm{g} / \mathrm{ml} \mathrm{PF} 4$. However, at a given concentration of heparin, doubling of the PF4 concentration or reducing it by $50 \%$ led to complete loss or a marked reduction of reactivity. When these studies were repeated with fresh heparin from the same manufacturer (lot 2), complexes optimal for IgG binding were formed at higher heparin/ $\mathrm{PF} 4$ ratios, e.g., $0.3 \mathrm{U} / \mathrm{ml}$ heparin and $10 \mu \mathrm{g} / \mathrm{ml} \mathrm{PF} 4$, or $1.0 \mathrm{U} / \mathrm{ml}$ heparin and $25 \mu \mathrm{g} / \mathrm{ml} \mathrm{PF} 4$ (Fig. $1 \mathrm{~B}$ ). With complexes formed at greater concentrations of heparin, IgG binding diminished to an OD of $\sim 0.40$, but remained above background even with a ratio of $10 \mathrm{U} / \mathrm{ml}$ heparin per $10 \mu \mathrm{g} / \mathrm{ml} \mathrm{PF} 4$. The basis for the variable behavior of different lots of heparin was examined by studying vials of heparin of different ages. Each of two vials of fresh heparin (lot 2 ) and six of nine vials that were several months postoutdate (lot 1) produced a pattern similar to that shown in Fig. $1 B$, whereas three of nine outdated vials produced the pattern shown in Fig. $1 A$. The anticoagulant activities of heparins from lots 1 and 2 were indistinguishable, as measured by their abilities to prolong the partial thromboplastin time of normal plasma (data not shown). Both in-date (expiration 1996) and outdated (1991) heparin from the other two manufacturers (Lyphomed and Upjohn) yielded patterns similar to those shown in Fig. $1 B$. Regardless of the lot of heparin used, binding of IgG to heparin / PF4 complexes was abolished when heparin at a concentration of $1.0 \mathrm{U} / \mathrm{ml}$ was added to plasma before it was incubated with the immobilized complexes (data not shown). Results similar to those shown for patient 1 in Fig. 1, $A$ and $B$ were obtained with plasma from eight other patients. Three patients were not studied in this way because only small amounts of plasma were available. No significant binding to heparin/PF4 complexes was seen with plasma from 18 normal subjects. Recombinant human PF4 behaved identically to PF4 isolated from human platelets in this assay (data not shown).

Reactions of plasma from HITP patients, patients with other types of thrombocytopenia, and normal subjects with immobilized heparin/PF4 complexes. Heparin/PF4 complexes formed at a ratio of $0.05 \mathrm{U} / \mathrm{ml}$ heparin (lot 1 ) and $10 \mu \mathrm{g} / \mathrm{ml}$
A

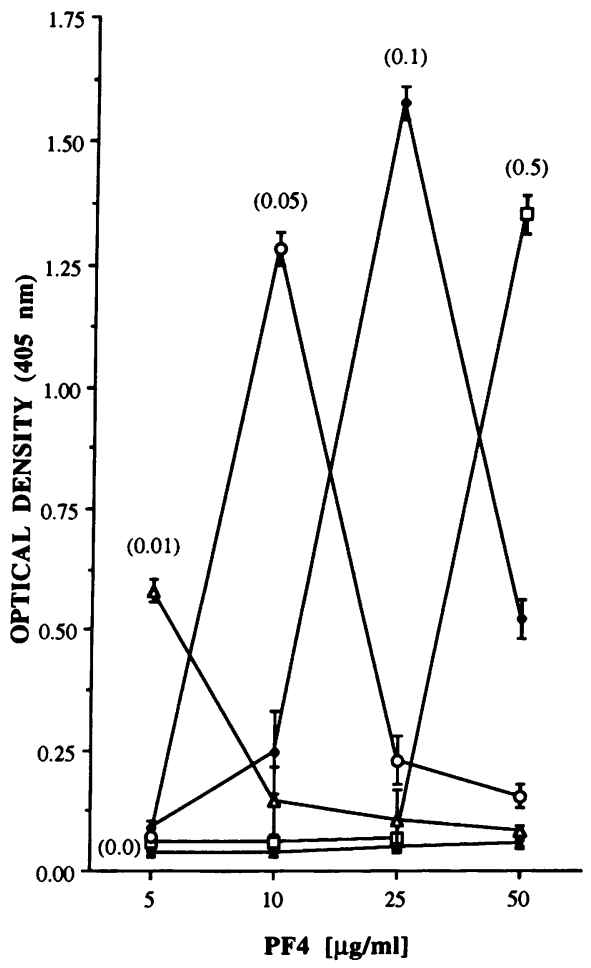

B

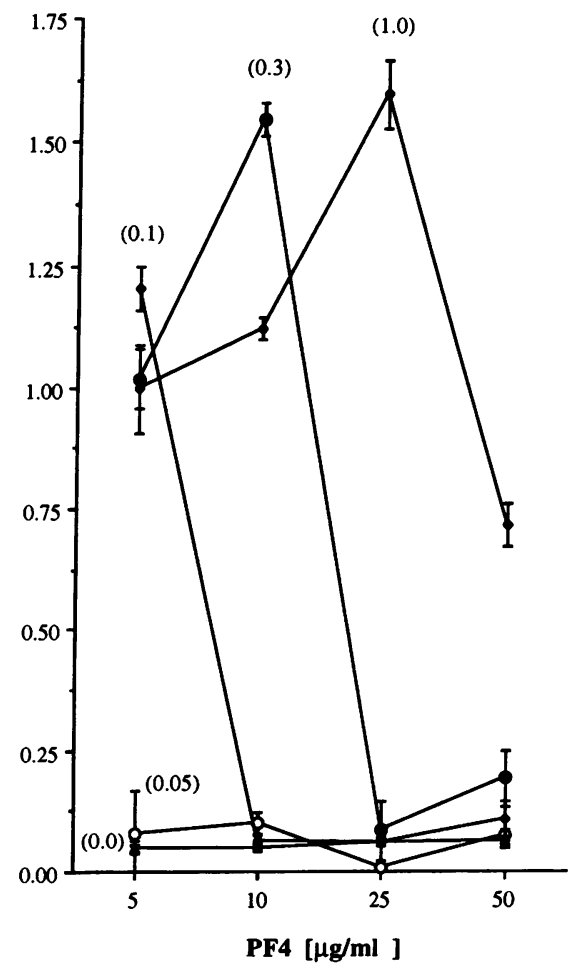

Figure 1. Binding of IgG from plasma (diluted 1:50) of patient no. 1 to immobilized complexes of PF4/heparin formed at different ratios of the reactants (average of triplicate determinations). Concentration of heparin $(\mathrm{IU} / \mathrm{ml})$ is shown in parentheses. Results shown in $A$ were obtained with heparin from a vial several months postoutdate (lot 1) and those in $B$ with freshly purchased heparin outdating in 1996 (lot 2). With lot 1 , heparin at 0.05 and $0.1 \mathrm{U} / \mathrm{ml}$ reacted with PF4 at 10 and $25 \mu \mathrm{g} / \mathrm{ml}$, respectively, to form complexes recognized by antibody $(A)$. At a given concentration of heparin from lot 2, complexes optimal for antibody binding were formed with about one-sixth the amount of PF4 required with heparin from lot $1(B)$. PF4 alone, plated at concentrations ranging from 5 to $50 \mu \mathrm{g} / \mathrm{ml}$, did not bind IgG (X-X). Error bars indicate $\pm 2 \mathrm{SD}$. 
PF4, plated, and stored for $90 \mathrm{~d}$ at $4{ }^{\circ} \mathrm{C}$ reacted with antibody as well as freshly prepared complexes and were used for further studies. Reactions of plasma (diluted 1:50) from the 12 patients with HITP against heparin/PF4 complexes prepared at this ratio are shown in Fig. $2 A$ and $B$. Each of the 12 samples contained IgG antibodies that bound to heparin/PF4 complexes (Fig. $2 A$ ). Three plasmas (nos. 3, 5, and 9) also reacted with PF4 alone, but less strongly than with the complexes. In each case, binding of IgG to heparin/PF4 complexes was reduced to the level obtained with immobilized PF4 alone by adding heparin to the wells at a concentration of $0.15 \mathrm{U} / \mathrm{ml}$ before the addition of plasma (Fig. $2 \mathrm{~A}$ ). This concentration of heparin had no effect on the binding of four quinine- or quinidine-induced platelet antibodies or four antibodies specific for the P1 ${ }^{A 1}$ alloantigen to immobilized GPIIb/IIIa complex (16), and did not appear to remove immobilized PF4 from the wells since the binding of goat antibody specific for human PF4 was unaffected (data not shown). As shown in Fig. $2 B$, five of the plasmas (nos. 2, 3, 5, 6, and 7) also contained IgM antibodies reactive with PF4/heparin. As with the IgG antibodies, binding was reduced to the value obtained with PF4 alone by added heparin. None of 18 normal plasmas used at 1:10 and 1:50 dilutions contained IgG or IgM that bound in significant quantities to heparin/PF4 complexes.
Plasma from 50 patients with other immune platelet disorders ( 19 with autoimmune thrombocytopenia, 14 with druginduced thrombocytopenia, 6 with posttransfusion purpura, and 11 women who had given birth to an infant with neonatal alloimmune thrombocytopenia) was also tested in the ELISA. 47 of the 50 samples gave negative reactions for IgG antibody at 1:10 dilution. The remaining three (two with posttransfusion purpura and one with autoimmune thrombocytopenia) gave positive reactions inhibitable with excess heparin at 1:10 but were negative at 1:50. The same three patients gave positive reactions for IgM antibodies at 1:10 and 1:50, but were negative at $1: 100$.

Sensitivity of the ELISA for detection of antibody. Reactions of the 12 HITP plasmas at various dilutions in the ELISA and in the serotonin release test are shown in Table I. At a dilution of 1:100, only two samples gave positive serotonin release tests, but the ELISA was positive with all 12 at 1:200 and with 9 at 1:500.

Heparin-induced IgG, but not IgM antibodies, bind to platelets in the presence of heparin/PF4 complexes. A mixture of heparin (lot 1)/PF4 (0.05 U/ml heparin, $10 \mu \mathrm{g} / \mathrm{ml} \mathrm{PF4)} \mathrm{and}$ patient plasma (diluted 1:10) was added to $10^{7}$ platelets in a final volume of $50 \mu \mathrm{l}$ and incubated for $60 \mathrm{~min}$ at room temperature with occasional shaking. After three washes in PBS, pH

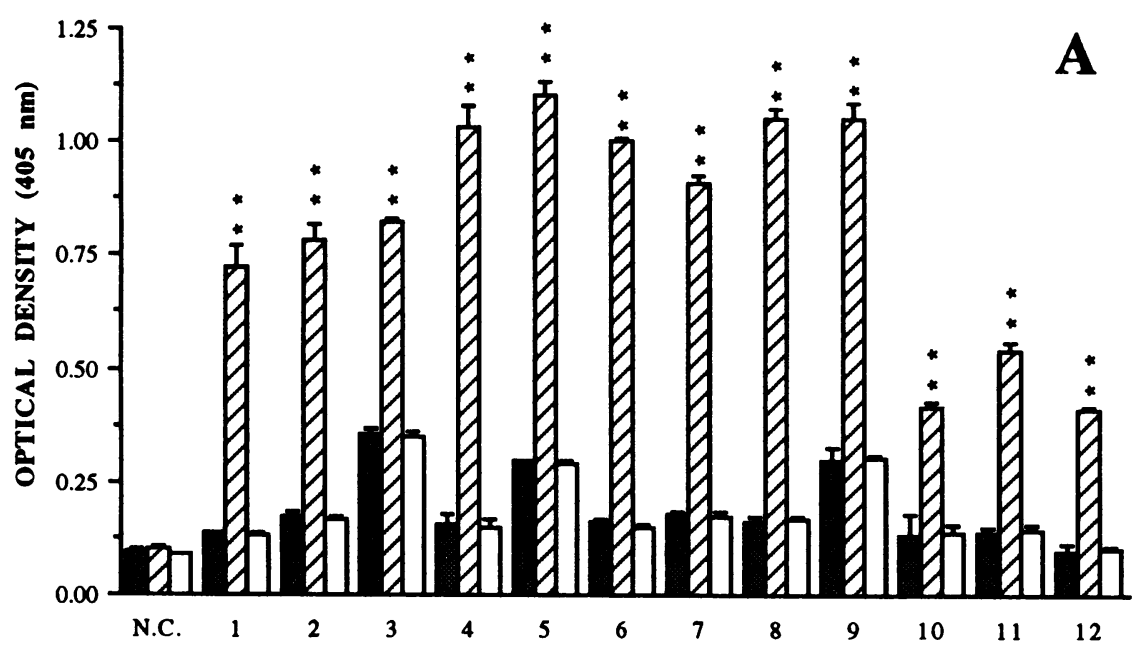

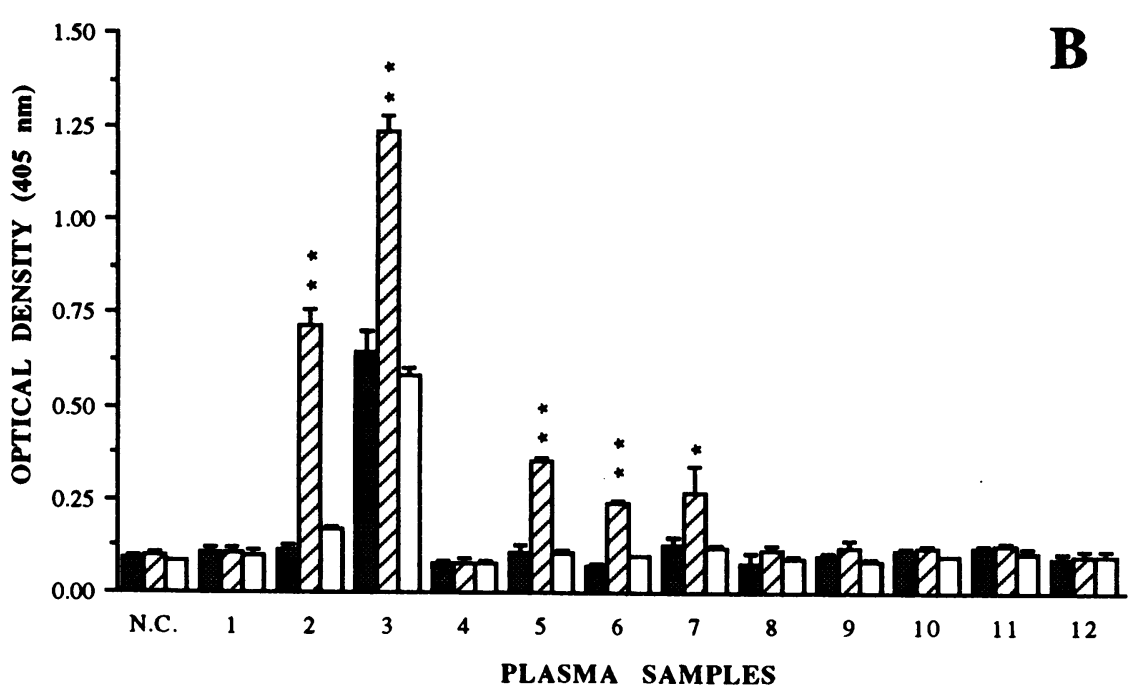

Figure 2. Binding of $\operatorname{IgG}(A)$ and $\operatorname{IgM}(B)$ from plasma (diluted 1:50 in PBS) of 12 patients with heparin-induced thrombocytopenia to immobilized heparin/PF4 complexes formed at $0.05 \mathrm{U} / \mathrm{ml}$ heparin (lot 1 )/ $10 \mu \mathrm{g} /$ $\mathrm{ml} \mathrm{PF} 4$ (average of triplicate determinations). Each of the plasma samples deposited signifcant quantities of IgG on immobilized complexes ( hatched bars) relative to immobilized PF4 alone ( $A$, shaded bars). Addition of 0.15 $\mathrm{U} / \mathrm{ml}$ heparin to plasma reduced the strength of all reactions (open bars) to the values obtained with immobilized PF4 alone. Average values for IgG binding obtained with 10 different normal plasmas are shown at the left (N.C.). Binding of IgM under the same experimental conditions is shown in $B$ (hatched bars). 5 of the 12 plasmas deposited significant quantities of IgM on heparin/PF4 complexes. Error bars indicate mean +2 SD. ${ }^{* *} P<0.001$; ${ }^{*} P<0.01$. 
Table I. Relative Sensitivity of the Serotonin Release and ELISAS for Detection of Heparin-induced (IgG) Antibodies in 12 Patients with HITP

\begin{tabular}{lccccc}
\hline & \multicolumn{5}{c}{ No. of positive reactions } \\
\cline { 2 - 6 } \multicolumn{1}{c}{ Assay } & Undiluted & $1: 10$ & $1: 100$ & $1: 200$ & $1: 500$ \\
\hline Serotonin release & 12 & 12 & 2 & NT & NT \\
ELISA & 12 & 12 & 12 & 12 & 9 \\
\hline
\end{tabular}

NT, not tested.

7.2, containing $50 \mu \mathrm{g} / \mathrm{ml} \mathrm{PGE}$, bound $\mathrm{IgG}$ and IgM were measured by flow cytometry. As shown in Fig. 3 for patient 1 , IgG was deposited on target platelets incubated with patient plasma under these conditions, but not when platelets were incubated with plasma alone, plasma and heparin alone, or plasma and PF4 alone. Platelets activated with thrombin receptor peptide consistently bound $\sim 30 \%$ more IgG than nonactivated platelets (data not shown). Binding of IgG similar to that shown in Fig. 3 was also observed with plasma from six other patients (3-5, 7, 8, and 12) when incubated with platelets in the presence of heparin and PF4. Negative reactions were obtained with plasma from the remaining five patients. No binding of $\operatorname{IgG}$ to platelets was observed with any of 10 normal plasmas under the same conditions. In the seven positive reactions, mean platelet fluorescence intensity ranged from 2.75 to

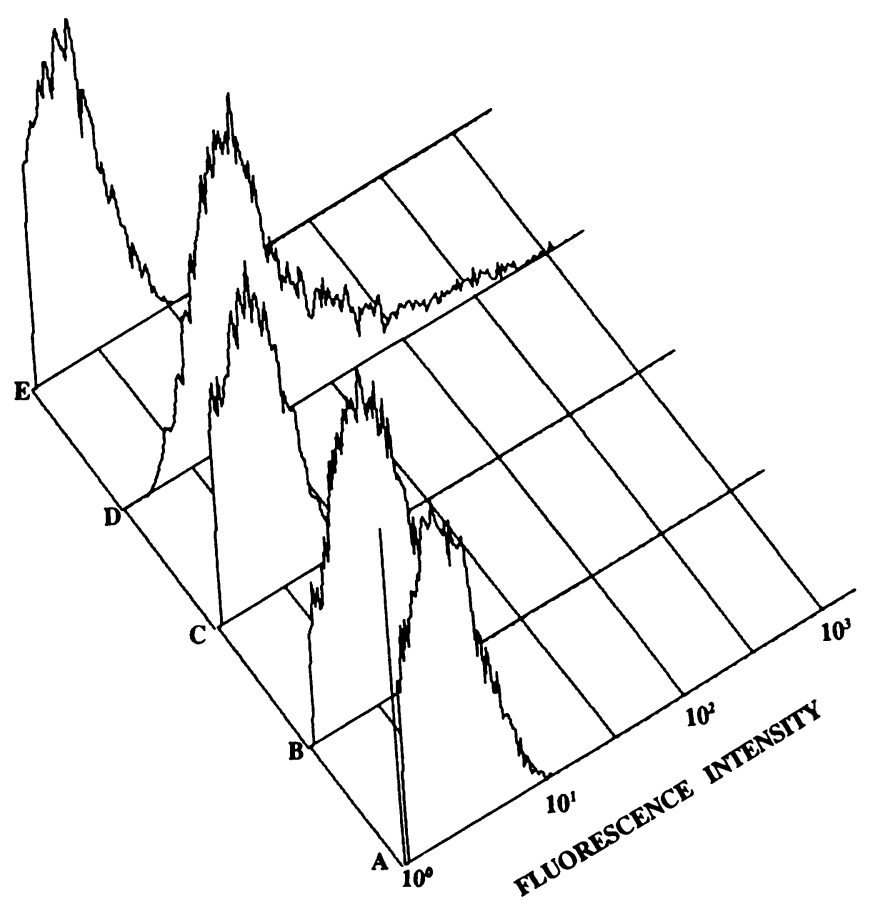

Figure 3. Binding of IgG (fluorescence intensity) to resting platelets incubated with plasma from patient 1 . $(A)$ Plasma alone; $(B)$ plasma plus $10 \mu \mathrm{g} / \mathrm{ml} \mathrm{PF} 4$; $(C)$ plasma plus $0.05 \mathrm{U} / \mathrm{ml}$ heparin (lot 1 ); $(D)$ plasma plus $10 \mu \mathrm{g} / \mathrm{ml} \mathrm{PF} 4$ and $0.05 \mathrm{U} / \mathrm{ml}$ heparin; $(E)$ same mixture as $D$ against platelets pretreated with monoclonal antibody IV.3 ( Fc $\gamma$ RII receptor specific). Blockade of Fc $\gamma$ RII with IV.3 completely abolished IgG binding. Similar inhibition was obtained with $0.15 \mathrm{U} /$ $\mathrm{ml}$ heparin (not shown). Number of events are plotted on the perpendicular axis.
9.5 (average, 5.6) times the value obtained with heparin alone or PF4 alone. With 10 normal plasmas, this ratio never exceeded 1.5. IgG binding to platelets from each of the seven positive plasmas in the presence of heparin/PF4 was totally inhibited by monoclonal antibody IV. 3 at $10 \mu \mathrm{g} / \mathrm{ml}$ (Fig. $3 E$ ), a concentration sufficient to block platelet Fc $\gamma$ RII receptors (15). However, IgG binding was unaffected by monoclonals AP-1 and AP-2 specific for glycoproteins Ib and IIb/IIIa, respectively, at a concentration of $10 \mu \mathrm{g} / \mathrm{ml}$. Binding of IgG to platelets in the presence of heparin/PF4 was rapid and could be detected even when platelets were isolated immediately after the incubation was started. Under the same conditions used to measure binding of $\operatorname{IgG}$ to platelets, no binding of $\operatorname{IgM}$ was detected with any of the 12 plasmas using an IgM-specific polyclonal probe.

Heparin-induced IgG and IgM antibodies bind to cultured HUVEC in the presence of PF4 alone. Suspensions of $5 \times 10^{5}$ HUVEC were incubated with $50 \mu$ l of patient plasma diluted $1: 10$ in PBS containing $10 \mu \mathrm{g} / \mathrm{ml}$ PF 4 for $60 \mathrm{~min}$ at $4^{\circ} \mathrm{C}$. After washing three times, bound IgG and IgM were determined by flow cytometry. As illustrated in Fig. 4 for patient 2, significant quantities of $\operatorname{IgG}$ were deposited on endothelial cells in the presence (Fig. $4 \mathrm{C}$ ) but not in the absence (Fig. $4 \mathrm{~A}$ ) of PF4. The IgG binding was abolished when $0.05 \mathrm{U} / \mathrm{ml}$ heparin (lot 1) was added to the plasma/PF4 mixture before incubation with HUVEC (Fig. $4 D$ ) and did not occur with plasma containing heparin alone $(0.05 \mathrm{U} / \mathrm{ml})$ (Fig. $4 \mathrm{~B})$. Similar binding

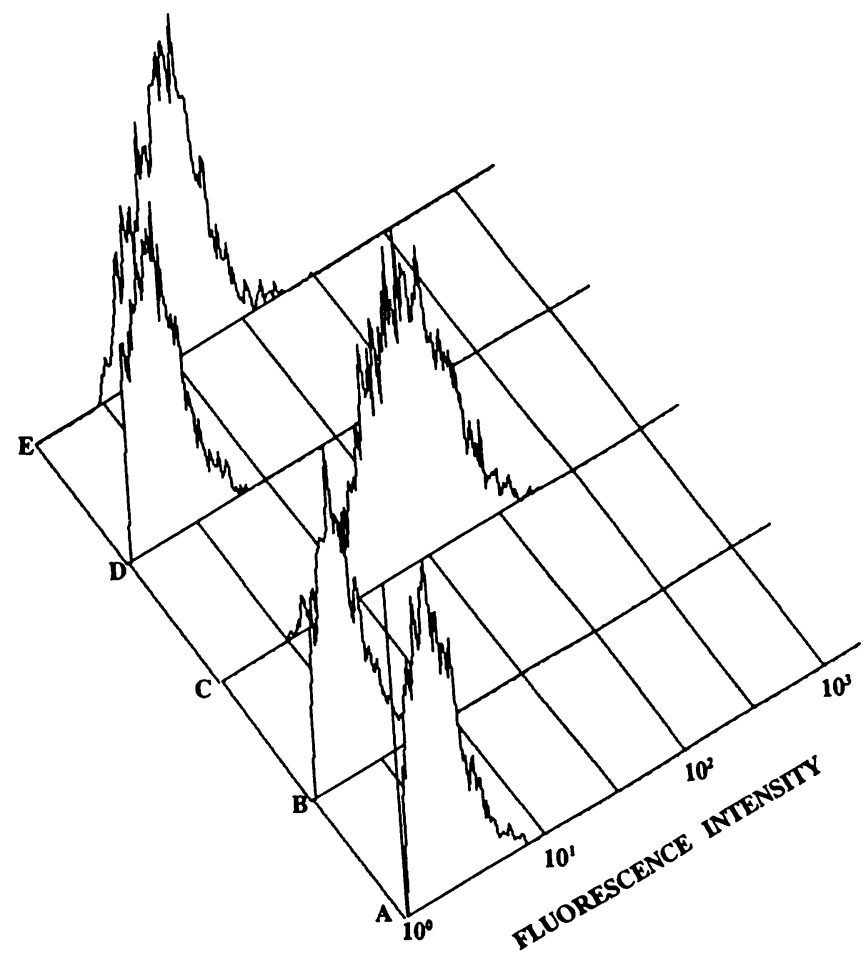

Figure 4. Binding of $\operatorname{IgG}(A-D)$ and $\operatorname{IgM}(E)$ from plasma of patient 2 to cultured HUVEC. $(A)$ Plasma alone; $(B)$ plasma plus $0.05 \mathrm{U} / \mathrm{ml}$ heparin (lot 1 ); $(C$ ) plasma plus $10 \mu \mathrm{g} / \mathrm{ml}$ PF4; $(D)$ plasma plus $0.05 \mathrm{U} / \mathrm{ml}$ heparin and $10 \mu \mathrm{g} / \mathrm{ml} \mathrm{PF} 4 ;(E)$ binding of IgM from plasma containing $10 \mu \mathrm{g} / \mathrm{ml}$ PF4. Both $\operatorname{IgG}(C)$ and $\operatorname{IgM}(E)$ bound to HUVEC in the presence of PF4 alone. This binding was completely inhibited by heparin $(D)$. IgM binding was similarly inhibited by heparin (not shown). 
of IgG to HUVEC was observed with plasma from the other 11 patients (not shown). No IgG binding was observed with any of 10 normal plasmas in the presence of PF4. Mean fluorescence intensity of HUVEC incubated with the 12 patient plasmas containing PF4 ranged from 2.0 to 16.5 (average, 6.4) times the value obtained with untreated HUVEC or HUVEC treated with normal plasma containing PF4. With 10 normal plasmas, this ratio was always $<1.5$.

Each of the five plasmas shown to contain IgM antibodies reactive with heparin/PF4 complexes by ELISA $(2,3$, and 5-7) also exhibited IgM binding to HUVEC in the presence of PF4 (shown for patient 2 in Fig. $4 E$ ) but not in the absence of PF4. Mean fluorescence intensity of IgM binding to HUVEC incubated with plasma of these five patients ranged from 2.1 to 5.0 (average, 3.22 ) times control. With 10 normal plasmas and with plasma from the other 7 patients, this ratio was always $<1.5$. Binding of IgG and IgM to HUVEC in the presence of PF4 was unaffected by pretreatment of the target cells with the Fc $\gamma$ RII-specific monoclonal antibody IV.3 at $10 \mu \mathrm{g} / \mathrm{ml}$.

HUVEC incubated with $10 \mu \mathrm{g} / \mathrm{ml}$ PF4 and then washed also bound IgG from subsequently added patient plasma, but not normal plasma (data not shown). This binding was abolished by treating the PF4-treated HUVEC with $0.05 \mathrm{U} / \mathrm{ml}$ heparin (lot 1 ) before adding patient plasma. In these studies, binding of PF4 to HUVEC was demonstrated by incubating the PF4-treated cells with goat anti-PF4, followed by DTAF-labeled donkey anti-goat IgG and analysis by flow cytometry (data not shown). When the PF4-coated cells were incubated with $0.05 \mathrm{U} / \mathrm{ml}$ heparin before analysis, no binding of antiPF4 antibody was observed.

\section{Discussion}

These findings indicate that platelet-activating, heparin-induced antibodies are specific for PF4/heparin complexes and can be detected in a microtiter plate assay using immobilized complexes as targets, in confirmation of Amiral et al. (9). Amiral et al. used a ratio of $0.15 \mathrm{U} / \mathrm{ml}$ heparin per $20 \mu \mathrm{g} / \mathrm{ml}$ recombinant PF4 in their studies without specifying why these quantities were chosen. We found that with fresh heparin (lot 2 ), and with six of nine vials of heparin several months postoutdate ( lot 1), target complexes formed at a ratio of $\sim 0.3 \mathrm{U} / \mathrm{ml}$ heparin per $10 \mu \mathrm{g} / \mathrm{ml} \mathrm{PF} 4$ were most effective in antibody binding (Fig. $1 \mathrm{~B}$ ). With three of nine vials of outdated heparin, a ratio of $0.05 \mathrm{U} / \mathrm{ml}$ heparin per $10 \mu \mathrm{g} / \mathrm{ml} \mathrm{PF} 4$, similar to the ratio used by Amiral et al. (9), was optimal (Fig. $1 A$ ). It is apparent from Fig. 1 that with either lot of heparin, the ratio of heparin / PF4 used to form target complexes is important, especially with vials yielding the pattern shown in Fig. $1 A$.

The molecular mass of the human PF4 tetramer is $\sim 32,000$ daltons $(19,20)$. The PF4 gene has been cloned and sequenced $(21,22)$ and the structure of the PF4 tetramer has been partially characterized $(20,23,24)$. Heparin is thought to bind to lysine-rich domains carried on alpha-helical structures near the COOH terminus of each PF4 monomer $(20,24,25)$. Assuming a specific activity of heparin of $174 \mathrm{U} / \mathrm{mg}$ (see Methods) and an average molecular mass of 12,000 daltons for pharmaceutical heparin $(25,26)$, the molar ratio of heparin/ PF4 required for optimum complex formation with fresh heparin (lot 2 ) can be calculated to be $\sim 1: 2$. With the older lots of heparin yielding the pattern shown in Fig. $1 \mathrm{~A}$, the corresponding ratio would be $\sim 1: 12$ assuming the same average molecu- lar mass for heparin, i.e., no degradation. Recent studies suggest that the heparin binding domains of the bovine PF4 tetramer, which is closely homologous to human PF4, can be saturated by a single molecule of heparin containing at least 18 monosaccharide residues ( $\sim 6,000$ daltons) $(24)$. On this basis, even the largest heparin molecules present in a pharmaceutical preparation, e.g., 35,000 daltons, might be expected to bind no more than five or six PF4 molecules. Loscalzo et al. (25) found that human PF4 appeared to bind to unfractionated porcine intestinal heparin at a maximum molar ratio of $4: 1$. In the light of these studies, a heparin/PF4 molar ratio of $\sim 1: 12$ is improbable and it seems likely that the requirement for higher concentrations of PF4 to form optimal heparin/PF4 complexes with several of the older heparin preparations reflects the need to overcome an inhibitory effect of smaller heparin fragments that develop during storage. In support of this possibility, we have found in preliminary studies that heparin fragments consisting of six or eight saccharide units (Enzyme Research Laboratories, South Bend, IN) are incapable of forming complexes with PF4 to which antibody binds.

Studies with more homogeneous heparin preparations should help to define more precisely the composition of the heparin / PF4 complexes for which heparin-induced antibodies are specific. It seems possible that the antibody binding sites are combinatorial epitopes created by the apposition of heparin and PF4, analogous to target epitopes consisting of platelet glycoprotein complexed with quinine hypothesized to explain the binding of quinine-induced antibodies to the platelet glycoprotein IIb/IIIa complex (27).

5 of the 12 plasmas we studied contained both IgG and IgM immunoglobulins recognizing PF4/heparin complexes (Fig. 2 $B)$. To our knowledge, only one example of a possible heparininduced IgM antibody has been described previously (28). The weak binding of antibodies from three patients to PF4 alone (Fig. $2 A$ ) is currently unexplained, but is consistent with the possibility that some individuals produce PF4-specific antibodies together with those that recognize heparin/PF4 complexes. The sensitivity of the microtiter tray ELISA was remarkable, in that each of 12 plasmas containing heparin-induced antibodies gave positive reactions at a dilution of $1: 200$ and 9 were positive at 1:500, whereas the serotonin release test was positive at a dilution of 1:100 with only 2 (Table I). It is generally agreed that serotonin release is more sensitive than the commonly used platelet aggregation test $(3,11,29)$. Further studies are required to characterize fully the specificity of the ELISA for the diagnosis of HITP. At a plasma dilution of $1: 200$, all 12 HITP plasmas were positive for IgG binding, whereas 18 normal plasmas and 50 plasmas from patients with other types of immune thrombocytopenia were negative at 1:50. However, 3 of the 50 patient plasmas were positive for $\operatorname{IgG}$ at $1: 10$. Plasma from the same three patients contained stronger (1:50) IgM antibodies reactive with heparin/PF4 complexes in ELISA. It is not currently known whether any of these individuals were previously exposed to heparin. At a dilution of 1:100, only plasma from patients with HITP gave positive reactions for IgM. Studies are in progress to optimize the ELISA for sensitivity and specificity and to define further the clinical significance of positive reactions. It will be of great interest to learn whether IgM antibodies, which may not be capable of causing thrombocytopenia ( see discussion to follow), signal a primary immune response in patients at risk to develop HITP and thrombosis.

In the presence of PF4 and heparin at an optimum ratio, 
heparin-induced IgG antibodies from 7 of the 12 patients bound in significant quantities to resting target platelets (Fig. 3 ). This binding occurred rapidly (within seconds) and was completely inhibited by monoclonal IV. 3 specific for the platelet Fc $\gamma$ RII receptor. No detectable IgG binding occurred in the presence of heparin alone. Activated platelets, which express increased numbers of $\mathrm{Fc} \gamma$ receptors (30), bound more IgG than nonactivated platelets. The most plausible explanation for these findings is that the IgG binds to heparin/PF4 to form immune complexes which, in turn, bind to platelet Fc $\gamma$ RII. Failure of IgM antibodies to bind under similar conditions would be expected, since platelets are not known to carry a receptor for IgM Fc. It is not apparent why plasma from five patients failed to exhibit IgG binding to platelets. Two of the nonbinding plasmas contained both IgG and IgM antibodies, and it seems possible that they formed mixed aggregates of IgG and IgM incapable of binding to platelet Fc $\gamma$ RII. Alternatively, platelets expressing high levels of $\mathrm{Fc} \gamma \mathrm{RII}$ may be required to detect immune complex binding with plasma of some patients (31).

Human endothelial cells express proteoglycan molecules consisting of a protein core to which is attached sulfated oligosaccharides with heparin-like properties (32). Only a small fraction of these molecules regulate the activity of antithrombin III, but all probably react with PF4 (32). Binding of PF4 to endothelial cell proteoglycans $(33,34)$ is thought to account for its rapid clearance from the circulation after intravenous injection (35-37). Our studies demonstrate that binding of PF4 to HUVEC creates a target for heparin-induced IgG and IgM immunoglobulins (Fig. 4). Cines et al. (38) described the binding of heparin-induced antibodies to HUVEC monolayers in the absence of added PF4 and concluded that the antibodies are specific for heparan sulfate on the cell surface, but these findings were not reproduced by another group (39). None of the 12 plasma samples that we studied deposited IgG or IgM on HUVEC in the absence of added PF4. In their studies, Cines et al. (35) used $50 \%$ serum that had been absorbed to remove heparin, but may have contained significant amounts of PF4 released from platelets in the clotting process. Platelets in $1 \mathrm{ml}$ of normal blood contain $\sim 6 \mu \mathrm{g}$ PF4 $(20,37)$, and its release in the clotting process could produce a serum PF4 level in the range of $10 \mu \mathrm{g} / \mathrm{ml}$, about the concentration we found optimal to promote binding of antibody to HUVEC. Even in a thrombocytopenic patient, significant quantities of PF4 are likely to be present in serum. It seems possible that the findings of Cines et al., can be explained by PF4 contributed by serum to their reaction mixtures.

On the basis of these findings, it is possible to propose a new model for the pathogenesis of heparin-induced thrombocytopenia and thrombosis. Under normal conditions, only minute quantities $(\sim 3 \mathrm{ng} / \mathrm{ml})$ of PF4 are found in human plasma (37). However, significant amounts of PF4 are normally associated with endothelial cell proteoglycans (32). After intravenous injection of heparin, the plasma level of PF4 increases 15-30-fold and remains elevated for several hours, apparently because PF4 is mobilized by the injected heparin from endothelial cells (35-37). In most circumstances, heparin/PF4 complexes that circulate after heparin injection are of no clinical significance. In a patient with IgG antibodies specific for these complexes who is treated with heparin, however, the following sequence of events can be envisioned. (a) Minimal activation of circulating platelets by heparin alone $(40,41)$, or by im- mune complexes consisting of heparin, PF4, and IgG, leads to release of PF4 from platelet alpha-granules in a complex with chondroitin sulfate $(42,43) ;(b)$ circulating heparin displaces the chondroitin sulfate to form heparin/PF4 complexes (20, $44) ;(c)$ antibodies bind to heparin / PF4 to form immune complexes in close proximity to the platelet surface; $(d)$ these bind to platelet Fc $\gamma$ RII receptors, activate platelets, and release more PF4; $(e)$ the additional PF4 released reacts with heparin and IgG to form new immune complexes, promoting further platelet activation and causing thrombocytopenia; $(f)$ PF4 released from platelets in excess of the amount that can be neutralized by available heparin binds to heparan sulfate on endothelial cells to create targets for antibody, leading to antibodymediated endothelial injury and a predilection to thrombosis or disseminated intravascular coagulation. IgM antibodies, because of their greater capacity for complement activation, may be more destructive to endothelial cells than those of the $\mathrm{IgG}$ class.

Further studies will be required to test the validity of this model and its implications for the diagnosis and treatment of heparin-induced thrombocytopenia/thrombosis. Our findings provide added support for the use of inhibitors of platelet function in the treatment of patients with HITP. The demonstration that antibody binds only to heparin/PF4 complexes formed at certain ratios of heparin / PF4 suggests the possibility that in vitro studies may lead to the identification of agents that act therapeutically by disrupting or preventing the formation of complexes capable of binding antibody.

\section{Acknowledgments}

We are grateful to Drs. Rodger McEver, Clark Anderson, Robert Montgomery, Thomas Kunicki, and Mortimer Poncz for providing reagents used in these studies; to Mr. Roger Walcott, Mr. Paul Raisleger, and Ms. Janice Collins for excellent technical assistance; to Ms. Terry Bzdusek for her help in obtaining the necessary numbers of platelet concentrates; and to the Word Processing Department of The Blood Center for manuscript preparation.

This work was supported by grants HL-13629 and HL-44612 from the National Heart, Lung, and Blood Institute.

\section{References}

1. Weismann, R. E., and R. W. Tobin. 1958. Arterial embolism occurring during systemic heparin therapy. Arch. Surg. 76:219-227.

2. Roberts, B., F. E. Rosato, and E. F. Rosato. 1964. Heparin: a cause of arterial emboli? Surgery (St. Louis). 55:803.

3. Warkentin, T. E., and J. G. Kelton. 1991. Heparin-induced thrombocytopenia. Prog. Hemostasis Thromb. 10:1-34.

4. Edson, J. R. 1992. Heparin-induced thrombocytopenia. J. Lab. Clin. Med. 120:355-356.

5. Chong, B. H., W. R. Pitney, and P. A. Castaldi. 1982. Heparin-induced thrombocytopenia: association of thrombotic complications with heparin-dependent IgG synthesis that induces thromboxane synthesis and platelet aggregation. Lancet. ii:1246-1248.

6. Kelton, J. G., D. Sheridan, A. Santos, J. Smith, K. Steeves, C. Smith, C. Brown, and W. G. Murphy. 1988. Heparin-induced thrombocytopenia: laboratory studies. Blood. 72:925-930.

7. Green, D., K. Harris, N. Reynolds, M. Roberts, and R. Patterson. 1978. Heparin immune thrombocytopenia: evidence for heparin-platelet complex as the antigenic determinate. J. Lab. Clin. Med. 91:167.

8. Greinacher, A., I. Michels, and C. Mueller-Eckhardt. 1992. Heparin-associated thrombocytopenia: the antibody is not heparin specific. Thromb. Haemostasis. 67:545-549.

9. Amiral, J., F. Bridey, M. Dreyfus, A. M. Vissac, E. Fressinaud, M. Wolf, and D. Meyer. 1992. Platelet factor 4 complexed to heparin is the target for 
antibodies generated in heparin-induced thrombocytopenia. Thromb. Haemostasis. 68:95-96 (letter).

10. Vu, T. K. H., D. T. Hung, V. I. Wheaton, and S. R. Coughlin. 1991. Molecular cloning of a functional thrombin receptor reveals a novel proteolytic mechanism of receptor activation. Cell. 64:1057-1068.

11. Vu, T. K. H., V. I. Wheaton, D. T. Hung, I. Charo, and S. R. Coughlin 1991. Domain specifying thrombin-receptor interaction. Nature (Lond.) 353:674-677.

12. Sheridan, D., C. Carter, and J. G. Kelton. 1986. A diagnostic test for heparin-induced thrombocytopenia. Blood. 67:27-30.

13. Thompson, A. R., and R. B. Counts. 1976. Removal of heparin and protamine from plasma. J. Lab. Clin. Med. 88:922-929.

14. Medici, I., A. DiMartino, G. Chela, L. Callegaro, and M. Prosdocimi. 1989. Improved method for purification of human platelet factor 4 by affinity and ion-exchange chromatography. Thromb. Res. 54:277-287.

15. Tomiyama, Y., T. J. Kunicki, T. F. Zipf, S. B. Ford, and R. H. Aster. 1992. Response of human platelets to activating monoclonal antibodies: importance of Fc $\gamma$ RII (CD32) phenotype and a level of expression. Blood. 80:2261-2268.

16. Visentin, G. P., K. Wolfmeyer, P. J. Newman, and R. H. Aster. 1990. Detection of drug-dependent, platelet-reactive antibodies by antigen-capture ELISA and flow cytometry. Transfusion (Phila.). 30:694-700.

17. Barbieri, B., G. Balconi, E. Dejana, and M. B. Donati. 1981. Evidence that vascular endothelial cells can induce the retraction of fibrin clots. Proc. Soc. Exp. Biol. Med. 68:204-207.

18. Balconi, G., and E. Dejana. 1986. Cultivation of endothelial cells: limitations and perspectives. Med. Biol. (Helsinki). 64:231-245.

19. Ryo, R., R. T. Proffitt, M. E. Poger, R. O'Bear, and T. F. Deuel. 1980 Platelet factor 4 antigen in megakaryocytes. Thromb. Res. 17:645-652.

20. Zucker, M. B., and I. R. Katz. 1991. Platelet factor 4: production, structure, and physiologic and immunologic action. Proc. Soc. Exp. Biol. Med. 198:693-702.

21. Poncz, M., S. Surrey, P. LaRocco, M. J. Weiss, E. F. Rappaport, T. M. Conway, and E. Schwartz. 1987. Cloning and characterization of platelet factor 4 cDNA derived from a human erythroleukemic cell line. Blood. 69:219-223.

22. Barone, A. D., J. Ghrayeb, U. Hammerling, M. B. Zucker, and G. J. Thorbecke. 1988. The expression in E coli of recombinant human platelet factor 4, a protein with immunoregulatory activity. J. Biol. Chem. 263:8710-8715.

23. St. Charles, R., D. A. Walz, and B. F. Edwards. 1989. The three-dimensional structure of bovine platelet factor 4 at 3.0A resolution. J. Biol. Chem. 264:2092-2099.

24. Stuckey, J. A., R. St. Charles, and B. F. P. Edwards. 1992. A model of the platelet factor 4 complex with heparin. Proteins Struct. Funct. Genet. 14:277287.

25. Loscalzo, J., B. Melnick, and R. I. Handin. 1985. The interaction of platelet factor 4 and glycosaminoglycans. Arch. Biochem. Biophys. 241:446-455.

26. Nieduszynski, I. 1989. General physical properties of heparin. In Heparin: Chemical and Biological Properties, Clinical Applications. D. A. Lane and U. Lindahl, editors. CRC Press, Inc., Boca Raton, FL. 51-63.

27. Visentin, G. P., P. J. Newman, and R. H. Aster. 1991. Characteristics of quinine- and quinidine-induced antibodies specific for platelet glycoproteins IIb and IIIa. Blood. 77:2668-2676.

28. Wahl, T. O., D. A. Lipschitz, and D. J. Stechschulte. 1978. Thrombocytopenia associated with antiheparin antibody. J. Am. Med. Assoc. 240:2560-2562

29. Favoloro, E. J., E. Bernal-Hoyos, T. Exner, and J. Koutts. 1992. Heparininduced thrombocytopenia: laboratory investigation and confirmation of diagnosis. Pathology. 24:177-183.

30. McCrae, K. R., S. J. Shattil, and D. B. Cines. 1990. Platelet activation induces increased Fc gamma receptor expression. J. Immunol. 144:3920-3927.

31. Chong, B. H., R. L. Pilgrim, M. A. Cooley, and C. N. Chesterman. 1993. Increased expression of platelet IgG Fc receptors in immune heparin-induced thrombocytopenia. Blood. 81:988-993.

32. Marcum, J. A., and R. D. Rosenberg. 1989. The biochemistry, cell biology, and pathophysiology of anticoagulantly active heparin-like molecules of the vessel wall. In Heparin: Chemical and Biological Properties Clinical Applications D. A. Lane and U. Lindal, editors. CRC Press, Inc., Boca Raton, FL. 275-294.

33. Busch, C., J. Dawes, D. S. Pepper, and A. Wasteson. 1980. Binding of platelet factor 4 to cultured human umbilical vein endothelial cells. Thromb. Res. 19:129-137.

34. Ryback, M. E., M. A. Gimbrone, Jr., P. F. Davies, and R. I. Handin. 1989. Interaction of platelet factor 4 with cultured vascular endothelial cells. Blood 73:1534-1539.

35. Dawes, J., C. W. Pumphrey, K. M. McLaren, C. V. Prowse, and D. S Pepper. 1982. The in vivo release of human platelet factor 4 by heparin. Thromb Res. 27:65-76.

36. Rao, A. K., S. Niewiarowski, P. James, J. C. Holt, M. Harris, B. Elfenbein and C. Bastl. 1983. Effect of heparin on the in vivo release and clearance of human platelet factor 4. Blood. 61:1208-1214.

37. O'Brien, J. R., M. D. Etherington, and M. Pashley. 1984. Intra-platelet platelet factor 4 (IP.PF4) and the heparin-mobilizable pool of PF4 in health and atherosclerosis. Thromb. Haemostasis. 51:354-357.

38. Cines, D. B., A. Tomaski, and S. Tannenbaum. 1987. Immune endothelial-cell injury in heparin-associated thrombocytopenia. N. Engl. J. Med. 316:581-589.

39. Foresti, V., G. Guareschi, A. Pediconi, N. Scolari, A. Vismara, and F. Confalonieri. 1988. Platelet aggregating IgG without antibodies to endothelial cells in a case of heparin-induced thrombocytopenia with thrombotic complication. Haematologica. 73:125-7.

40. Eika, C. 1972. The platelet aggregating effect of eight commercial heparins. Scand. J. Haematol. 9:480.

41. Zucker, M. B. 1974. Effect of heparin on platelet function. Thromb. Diath. Haemorrh. 33:63-65.

42. Huang, S. S., J. S. Huang, and T. F. Deuel. 1982. Proteoglycan carrier of human platelet factor 4. J. Biol. Chem. 257:11546.

43. Holt, J. C., and S. Niewiarowski. 1985. Biochemistry of alpha-granule proteins. Semin. Hematol. 22:151-163.

44. Handin, R. I., and H. J. Cohen. 1976. Purification and binding properties of human platelet factor 4. J. Biol. Chem. 251:4273-4282. 